\title{
The ionic strength effect on microcystin and natural organic matter surrogate adsorption onto PAC
}

\author{
Margarida Campinas *, Maria João Rosa \\ Centre of Marine and Environmental Research, Faculty of Marine and Environmental Sciences, University of Algarve, Campus de Gambelas, \\ 8005-139 Faro, Portugal
}

Received 7 December 2005; accepted 21 February 2006

Available online 17 April 2006

\begin{abstract}
This work aims to contribute to a better understanding of the ionic strength effect on microcystin and natural organic matter (NOM) surrogate adsorption by analyzing the importance of adsorbate molecular size, and surface concentration. Adsorption kinetics and/or isotherms were performed on PAC Norit SA-UF for four microcystin variants (MC-LR, MC-LY, MC-LW, MC-LF), and three NOM surrogates (salicylic acid (SA), tannic acid (TA), Aldrich humic acid (AHA)) at different solution ionic strengths. Results showed that the ionic strength effect depends upon the adsorbate surface concentration, cation charge (mono or divalent), and adsorbate molecular size. Potassium seemed not to affect the MC-LR adsorption, while calcium enhanced MC-LR kinetics and adsorption capacity. $\mathrm{K}^{+}$and, particularly, $\mathrm{Ca}^{2+}$ improved the adsorption kinetics of the other microcystin variants. For identical surface concentration and ionic strength, the impact of $\mathrm{K}^{+}$and $\mathrm{Ca}^{2+}$ on NOM surrogates depended on the adsorbate molecular size: $\mathrm{K}^{+}$effect was only observed for AHA, whereas $\mathrm{Ca}^{2+}$ caused no effect on SA adsorption, slightly enhanced TA adsorption, and greatly enhanced AHA adsorption. MC-LR isotherms with two salt concentrations $\left(\mathrm{KCl}_{\text {or }} \mathrm{CaCl}_{2}\right)$ indicated that, for the studied range of equilibrium surface concentration $(5.3-18.7 \mathrm{mg} / \mathrm{g})$, an enhanced adsorption regime prevails, and no transition regime was observed.
\end{abstract}

(C) 2006 Elsevier Inc. All rights reserved.

Keywords: Microcystins; PAC; Adsorption; NOM surrogates; Surface concentration; Ionic strength

\section{Introduction}

Cyanobacteria (blue-green algae) produce toxins as secondary metabolites under certain conditions of growth. At least a third of the 50 known genera of cyanobacteria are capable of producing toxins [1] posing a significant risk to water supplies when they occur in reservoirs, lakes, and rivers used as water sources. Cyanotoxins are currently divided into classes according to their modes of toxicity: hepatotoxins, which affect the liver (e.g., microcystins, nodularins, cylindrospermopsin); neurotoxins, causing damage to the nervous system (e.g., anatoxins, saxitoxins); cytotoxins; and endotoxins [2]. The first two of these are of most significance in relation to water supplies, and the most commonly occurring toxins are microcystins and anatoxins. Clear safe levels of maximum tolerable concentration are still under discussion, but the World Health Organization

\footnotetext{
* Corresponding author. Fax: +351289800 069 .

E-mail address: mcampina@ualg.pt (M. Campinas).
}

established a drinking water guideline value of $1.0 \mu \mathrm{g} / \mathrm{L}$ for microcystin-LR, one of the most commonly occurring hepatotoxins.

The high incidence of cyanotoxin detection in monitoring programs coupled with the recognized potential health problems has prompted investigation of toxin removal methods [3]. Conventional treatment using chemical coagulation is able to remove algal cells and therefore the cell-bound cyanotoxin (particulate form), but it is believed to be largely ineffective for removing extracellular soluble toxins; these require more advanced treatment using, for example, activated carbon and/or membrane filtration, such as ultrafiltration and nanofiltration [4], or oxidants such as ozone. Besides the narrow removal of microcystins, the possibility that conventional treatment will originate cell lysis with a subsequent release of cyanotoxins and other metabolites to drinking water has also been considered [5].

Adsorption onto powdered activated carbon retained by ultrafiltration modules (PAC/UF) is one of the most promising 
treatment technologies for cyanotoxin removal. PAC/UF success depends on efficient PAC adsorption and, in treating natural waters, two major challenges may occur: natural organic matter (NOM) and ionic strength variations. A better understanding of the effect of ionic strength on microcystin and NOM adsorption is necessary to optimize microcystin removal while maintaining high removal of the coexistent NOM, a major precursor of the undesired disinfection by-products. This is especially true when the integrated PAC/UF process is used, as NOM removal is very important to minimize membrane fouling.

Increasing ionic strength or divalent metal concentration has been reported to enhance humic matter adsorption [6-15]. Among several cations investigated, calcium has been shown to be the most effective, magnesium less effective, and sodium the least effective [7].

However, recent investigations indicate that the ionic strength effect depends on two adsorbate variables, namely surface concentration [16-18] and molecular size [11,19,20].

At low surface concentrations, direct surface-NOM electrostatic interactions are predominant. Therefore, adsorption driven by attractive electrostatic interactions can be expected to decrease with an increase in ionic strength (shielding effect) (adsorption reduced regime). At higher surface concentrations, molecules are very proximate and repulsive electrostatic interactions dominate. Adsorption becomes predominantly a physical surface-NOM attraction, possibly due to hydrophobic or aromatic ring interactions, and additional ions will reduce the repulsive forces, thus increasing the adsorption (adsorption enhanced regime). When several different mechanisms are evident in a system, an adsorption reduced regime may change to an adsorption enhanced regime- - crossover point"-with an increase in surface concentration [16-18]. Bjelopavlic et al. [18] confirmed the existence of crossover points in the adsorption isotherms undertaken for a NOM fraction (500-3000 Da) at two ionic strengths.

Regarding the ionic strength effect dependence on the adsorbate molecular size, Randtke and Snoeyink [19] reported that, in general, increasing concentrations of salts may significantly increase the adsorptive capacity of GAC for organic anions, particularly those of high molecular weight. Kilduff et al. [11] increased the ionic strength from 10 to $70 \mathrm{mM}$ and obtained a greater increase in $18-\mathrm{kDa}$ polystyrene sulfonate adsorption than in the $1.8 \mathrm{kDa}$ fraction. Li et al. [20] concluded that the calcium effect depended on the dissolved organic matter (DOM) used: increasing the calcium concentration greatly enhanced the adsorption capacity of humic acid, slightly enhanced DOM removal of raw colored water, and had no effect on the DOM remaining after treatment (coagulation/sedimentation/filtration). The authors stated that indirect interactions between calcium and humic acid were the major mechanisms that led to the enhanced capacity.

Summing up, inorganic salts are known to influence the adsorption of a variety of organic compounds, though studies on the ionic strength effect on microcystin adsorption are scarce. It is also important to analyze the relative importance of molecular size and surface concentration for the ionic strength effect, since there are studies evaluating each parameter separately, but an integrated study is still missing. In taking into account model compounds of different molecular size, it is also important to understand if microcystin-LR behavior can be predicted from surface concentration and molecular size. Therefore, the main objective of this study is to understand the impact of the ionic strength on the microcystin and NOM adsorption onto PAC, and particularly to study (1) the effect of mono- and divalent cation addition; (2) the dependence on surface concentration (searching for adsorption regime transition); and (3) the importance of the molecular size.

Competitive adsorption between microcystin variants and NOM surrogates will be addressed in a paper to follow.

\section{Materials and methods}

\subsection{Adsorbates}

The adsorbates used in this study were microcystins and three model organic compounds of different molecular weight and degrees of hydrophobicity to simulate some of the wide range of NOM present in freshwater: Aldrich humic acid (AHA), tannic acid (TA), and salicylic acid (SA).

Microcystins are cyclic heptapeptides that share a general structure containing five fixed amino acids and two variable $\mathrm{L}$-amino acids, designated as $\mathrm{X}$ and $\mathrm{Z}$. The most commonly occurring microcystin contains leucine in position $\mathrm{X}$ and arginine in position $\mathrm{Z}$ and is therefore called MC-LR [21]. Microcystins were produced and extracted from Microcystis aeruginosa laboratory-grown culture (Pasteur Culture Collection, PCC 7820). As described by Ribau Teixeira and Rosa [4], the cultures were centrifuged, the pellet was freeze-dried, and microcystins were then extracted in a $75 \%$ aqueous methanol during an $18 \mathrm{~h}$ period minimal. Prior to microcystin solutions preparation, methanol was rotary evaporated and the microcystins were dissolved in ultrapure water. The microcystin variants detected in HPLC chromatograms were MC-LR, MC-LY, MC-LW, and MC-LF (Table 1) and it was verified that the dominant microcystin variant was MC-LR, accounting for ca. $75 \%$ of total microcystins.

Commercially available Aldrich humic acid (AHA) was selected as a representative of fairly hydrophobic high-molecularweight organic compounds. It is a negatively charged polyelectrolyte due to the dominance of carboxylic acid groups [24]. Molecular weight of humic acids is difficult to determine, for they are mixed molecular compounds; however, values of 4100 , $3070,14,500$, and 3000-11,000 Da have been reported for

Table 1

Properties of microcystin variants identified in this study

\begin{tabular}{lllll}
\hline & MC-LR & MC-LY & MC-LW & MC-LF \\
\hline Amino acids (X and Z) & Leucine, & Leucine, & Leucine, & Leucine, \\
& arginine & tyrosine & tryptophane & phenylalanine \\
Molecular weight & 994 & 1001 & 1024 & 985 \\
Net charge, pH 7 & -1 & -2 & -2 & -2 \\
& & & -2 & \\
\cline { 2 - 5 } & Increasing hydrophobicity & \\
\hline
\end{tabular}

Note. Adapted from $[1,22,23]$. 
Table 2

Relevant characteristics of PAC Norit SA-UF

\begin{tabular}{ll}
\hline BET surface area $\left(\mathrm{m}^{2} / \mathrm{g}\right)$ & 1112 \\
Ash content $(\%)$ & 8.17 \\
Moisture $(\%)$ & 2 \\
Apparent density $\left(\mathrm{g} / \mathrm{cm}^{3}\right)$ & 0.16 \\
Geometric mean diameter $(\mu \mathrm{m})$ & 6 \\
Primary micropore $(<8 \AA)$ volume $\left(\mathrm{cm}^{3} / \mathrm{g}\right)$ & 0.343 \\
Secondary micropore $(8-20 \AA)$ volume $\left(\mathrm{cm}^{3} / \mathrm{g}\right)$ & 0.194 \\
Mesopore $(20-500 \AA)$ volume $\left(\mathrm{cm}^{3} / \mathrm{g}\right)$ & 0.357 \\
Micropore surface area $\left(\mathrm{m}^{2} / \mathrm{g}\right)$ & 733 \\
Mesopore surface area $\left(\mathrm{m}^{2} / \mathrm{g}\right)$ & 379 \\
\hline
\end{tabular}

Note. Adapted from [20,32,34].

AHA [25,26]. Prior to any experiment, the peat-based Aldrich humic acid was purified according to Elimelech and Hong [27] through repeated precipitation by a strong acid to remove bound iron and decrease the ash content. AHA stock solution was filtered through GF-C $(1.2 \mu \mathrm{m})$ and GF-F $(0.7 \mu \mathrm{m})$ filters prior to solution preparation.

Tannic acid (Sigma Chemicals) was selected as a representative of relatively hydrophilic organics with a molecular weight of approximately $1700 \mathrm{Da}$. It contains phenolic groups and is expected to have a higher competitive adsorption with MC-LR due to their similar molecular weight. TA has been used as a NOM surrogate [28-31].

Salicylic acid (SA) (reagent grade Merck) represents the hydrophilic low-molecular-weight fraction of NOM with a molecular weight of $138 \mathrm{Da}$. It contains a hydroxyl and a carboxyl group.

\subsection{Adsorbent}

Commercial PAC Norit SA-UF was used in this study. A number of previous studies have used this PAC for NOM and/or pesticide removal [20,32-34], and its properties are given in Table 2.

This activated carbon was chosen due to its high mesopore and secondary micropore volume, an important characteristic for MC-LR adsorption, as concluded by Donati et al. [35] and Pendleton et al. [36]. Based on molecular models, the first authors estimated that the MC-LR diameter varies between 1.2 and $2.6 \mathrm{~nm}$, consistent with the correlation between MC-LR adsorption and mesopore volume. In addition, the low PAC particle diameter seems to be advantageous for fast adsorption kinetics and for its retention on ultrafiltration modules (low ratio of PAC particles to UF feed channels).

Surface charge determination was also undertaken by potentiometric titration of PAC electrolyte solutions $(0.01$ and $0.3 \mathrm{M}$ $\mathrm{NaCl}$ ), as described by Bjelopavlic et al. [18]. The variation of surface net charge of PAC Norit SA-UF with $\mathrm{pH}$ is shown in Fig. 1.

PAC Norit SA-UF displays a positive net charge for $\mathrm{pH}$ values lower than 9.6, the point of zero charge $\left(\mathrm{pH}_{\mathrm{zc}}\right)$.

Prior to use in all experiments, PAC was dried overnight in a $110{ }^{\circ} \mathrm{C}$ oven to remove excess water and was cooled in a desiccator. Once cooled, the desired amount of carbon, not less than $2 \mathrm{mg}$, was weighted on a 4-point scale (Mettler AE 240).

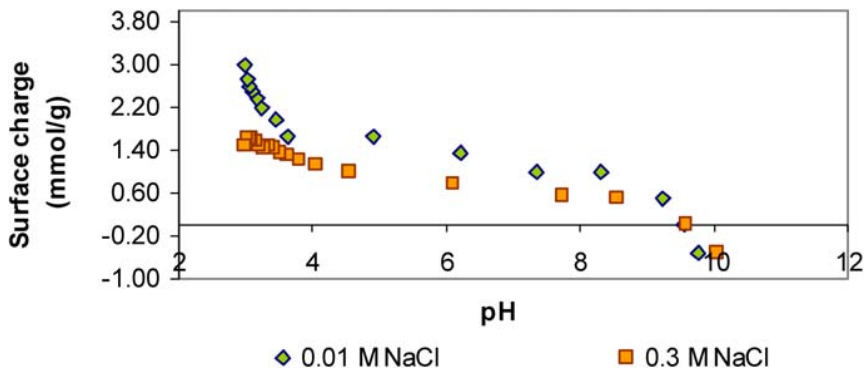

Fig. 1. Surface charge versus $\mathrm{pH}$ of PAC Norit SA-UF.

\subsection{Model solution preparation}

Organic free solutions were prepared using ultrapure Milli-Q water. Four types of solutions were used, as detailed in Table 3: solutions of microcystins in ultrapure water, NOM surrogate (AHA, TA, or SA) in ultrapure water (single model solutions), microcystins in mono- $(\mathrm{KCl})$ and/or divalent $\left(\mathrm{CaCl}_{2}\right)$ electrolyte solution, and NOM surrogate in the same electrolytes.

\subsection{Analytical methods}

Samples were analyzed for conductivity, $\mathrm{pH}$, microcystins, and/or NOM surrogates (AHA, TA, SA).

Electrical conductivity (at $25^{\circ} \mathrm{C}$ ) and $\mathrm{pH}$ (at $20^{\circ} \mathrm{C}$ ) were analyzed electrometrically using a Crison GLP 32 conductimeter and a WTW pH 340 meter, respectively.

Microcystin samples were concentrated by solid phase extraction (isolute C18) cartridges, eluted with $90 \%$ methanol containing $0.1 \%$ trifluoracetic acid (TFA) (v/v), rotary evaporated, resuspended in $75 \%$ methanol, and analyzed by HPLC with a photodiode array detector in a Dionex Summit System, as described by Ribau Teixeira and Rosa [4] and following the procedure of Meriluoto and Spoof [37]. A C18 column (Merck Purospher STAR RP-18 endcapped, 3- $\mu$ m particles, LiChroCART $55 \times 4 \mathrm{~mm}$ ) was used, and the mobile phase consisted of Milli-Q water and acetonitrile, both with $0.05 \%$ TFA. Chromatograms were analyzed between 180 and $900 \mathrm{~nm}$, with a main detection at $238 \mathrm{~nm}$ for the typical microcystin spectra [37].

For NOM surrogates, calibration curves between UV absorbance and AHA, TA, and SA concentrations were established. The UV absorbance was measured on filtered samples (0.45- $\mu \mathrm{m}$ acrodisks) with a UV/vis spectrophotometer (Spectronic Unicam) at $254 \mathrm{~nm}$ for AHA samples, $215 \mathrm{~nm}$ for TA samples, and $210 \mathrm{~nm}$ for SA samples.

\subsection{Adsorption kinetics experiments}

The effects of the adsorbate molecular size and solution chemistry (monovalent and divalent ions) were investigated by measuring the adsorption kinetics for SA, microcystins (LR, LY, LW, LF), TA, and AHA at different solution ionic strengths. The range of molecular weights studied (138 to ca. 11,000 Da) was chosen to cover the usual NOM molecular weight.

The device used for the batch kinetic experiments was a jartest apparatus with four positions (Flocumatic, Selecta). 
Table 3

Conditions for kinetic and isotherm experiments

\begin{tabular}{|c|c|c|c|c|c|c|c|c|c|}
\hline & \multirow[t]{2}{*}{ Experiments } & \multirow{2}{*}{$\begin{array}{l}\mathrm{pH} \\
\left(20^{\circ} \mathrm{C}\right)\end{array}$} & \multirow{2}{*}{$\begin{array}{l}\text { Conductivity } \\
25{ }^{\circ} \mathrm{C}(\mu \mathrm{S} / \mathrm{cm})\end{array}$} & \multirow{2}{*}{$\begin{array}{l}\text { PAC } \\
(\mathrm{mg} / \mathrm{L})\end{array}$} & \multicolumn{5}{|c|}{ Initial concentrations $\left(C_{0}\right)$} \\
\hline & & & & & $\begin{array}{l}\text { NOM } \\
\text { surrogates } \\
(\mathrm{mg} / \mathrm{L})\end{array}$ & $\begin{array}{l}\text { MC-LR } \\
(\mu \mathrm{g} / \mathrm{L})\end{array}$ & $\begin{array}{l}\text { MC-LY } \\
(\mu \mathrm{g} / \mathrm{L})\end{array}$ & $\begin{array}{l}\text { MC-LW } \\
(\mu \mathrm{g} / \mathrm{L})\end{array}$ & $\begin{array}{l}\text { MC-LF } \\
(\mu \mathrm{g} / \mathrm{L})\end{array}$ \\
\hline \multirow[t]{4}{*}{ SA kinetics } & Milli-Q water & 4.08 & 23 & 20 & 1.6 & - & - & - & - \\
\hline & $2.5 \mathrm{mM} \mathrm{IS}(\mathrm{KCl})$ & 4.20 & 349 & 20 & 1.6 & - & - & - & - \\
\hline & $2.5 \mathrm{mM} \mathrm{IS}\left(\mathrm{KCl}+\mathrm{CaCl}_{2}\right)$ & 4.39 & 259 & 20 & 1.6 & - & - & - & - \\
\hline & $10 \mathrm{mM}$ IS $\left(\mathrm{KCl}+\mathrm{CaCl}_{2}\right)$ & 5.52 & 887 & 20 & 1.7 & - & - & - & - \\
\hline \multirow{7}{*}{$\begin{array}{l}\text { Microcystins } \\
\text { kinetics }\end{array}$} & Milli-Q water & 5.17 & 15 & 5 & - & 26 & 2.4 & 1.8 & 3.9 \\
\hline & 2 mM IS (KCl) & 5.17 & 291 & 5 & - & 22 & 2.0 & 1.8 & 2.9 \\
\hline & 10 mM IS (KCl) & 5.44 & 1407 & 5 & - & 22 & 2.0 & 1.8 & 2.9 \\
\hline & 100 mM IS (KCl) & 5.72 & 12,800 & 5 & - & 22 & 2.0 & 1.8 & 2.9 \\
\hline & $2 \mathrm{mM} \mathrm{IS}\left(\mathrm{KCl}+\mathrm{CaCl}_{2}\right)$ & 6.36 & 212 & 5 & - & 18 & 2.3 & 1.6 & 2.4 \\
\hline & 10 mM IS $\left(\mathrm{KCl}+\mathrm{CaCl}_{2}\right)$ & 6.56 & 884 & 5 & - & 18 & 2.3 & 1.6 & 2.4 \\
\hline & $100 \mathrm{mM}$ IS $\left(\mathrm{KCl}+\mathrm{CaCl}_{2}\right)$ & 7.10 & 6300 & 5 & - & 18 & 2.3 & 1.6 & 2.4 \\
\hline \multirow[t]{3}{*}{ TA kinetics } & Milli-Q water & 4.64 & 3 & 20 & 2.8 & - & - & - & - \\
\hline & $2.5 \mathrm{mM}$ IS $(\mathrm{KCl})$ & 4.64 & 352 & 20 & 2.9 & - & - & - & - \\
\hline & $2.5 \mathrm{mM} \mathrm{IS}\left(\mathrm{KCl}+\mathrm{CaCl}_{2}\right)$ & 4.40 & 260 & 20 & 2.8 & - & - & - & - \\
\hline \multirow[t]{4}{*}{ AHA kinetics } & Milli-Q water & 4.40 & 7 & 20 & 2.9 & - & - & - & - \\
\hline & $2.5 \mathrm{mM}$ IS $(\mathrm{KCl})$ & 6.08 & 353 & 20 & 2.8 & - & - & - & - \\
\hline & $2.5 \mathrm{mM} \mathrm{IS}\left(\mathrm{KCl}+\mathrm{CaCl}_{2}\right)$ & 5.16 & 219 & 20 & 2.6 & - & - & - & - \\
\hline & $2.5 \mathrm{mM} \mathrm{IS}\left(\mathrm{KCl}+\mathrm{MgSO}_{4}\right)$ & 5.39 & 243 & 20 & 2.6 & - & - & - & - \\
\hline \multirow{5}{*}{$\begin{array}{l}\text { Microcystins } \\
\text { isotherms }\end{array}$} & Milli-Q water & 6.36 & 24 & $8.7-21.3$ & - & 117 & 10 & 10 & 16 \\
\hline & $2.5 \mathrm{mM}$ IS $(\mathrm{KCl})$ & 5.46 & 357 & $8.7-23.5$ & - & 136 & 13 & 10 & 16 \\
\hline & 10 mM IS (KCl) & 5.44 & 1407 & $8.7-23.5$ & - & 135 & 12 & 10 & 15 \\
\hline & $2.5 \mathrm{mM} \mathrm{IS}\left(\mathrm{KCl}+\mathrm{CaCl}_{2}\right)$ & 5.57 & 284 & $8.7-21.3$ & - & 215 & 15 & 12 & 18 \\
\hline & $10 \mathrm{mM} \mathrm{IS}\left(\mathrm{KCl}+\mathrm{CaCl}_{2}\right)$ & 5.91 & 863 & $8.7-21.3$ & - & 198 & 13 & 9.1 & 14 \\
\hline \multirow[t]{3}{*}{ TA isotherms } & Milli-Q water & 4.28 & 4 & $250-600$ & 4.6 & - & - & - & - \\
\hline & $2.5 \mathrm{mM}$ IS (KCl) & 5.25 & 349 & $250-600$ & 4.2 & - & - & - & - \\
\hline & 10 mM IS (KCl) & 4.51 & 1420 & $250-600$ & 4.5 & - & - & - & - \\
\hline
\end{tabular}

Note. IS: ionic strength.

Before its application in the kinetic experiments, PAC was soaked overnight in ultrapure water to allow for complete wetting of the pores.

After preparation, the solutions stayed overnight and were previously stirred $(125 \mathrm{rpm})$ for $5 \mathrm{~min}$ before PAC addition. PAC was added and samples were taken at predetermined intervals over a 4-h period. Identical mixing (200 rpm) and temperature conditions $\left(21-23^{\circ} \mathrm{C}\right)$ were applied to all batch reactors. Other experimental conditions are detailed in Table 3.

\subsection{Equilibrium isotherms experiments}

Adsorption isotherms were performed for microcystins and tannic acid at different ionic strengths (Table 3). Solutions spiked with microcystins or tannic acid were added to 250$\mathrm{ml}$ bottles, leaving a $20-\mathrm{ml}$ headspace. PAC was added and the bottles were sealed and stirred $\left(250 \mathrm{rpm}, 23^{\circ} \mathrm{C}\right)$ for $65 \mathrm{~h}$ (the equilibrium time previously determined). The samples in each bottle were filtered through a $0.7-\mu \mathrm{m}$ glass fiber filter (GF-F Whatman) for PAC particles retention and were analyzed for microcystins (by HPLC-PDA) or for tannic acid (by $\mathrm{UV}_{215 \mathrm{~nm}}$ absorbance). The amount adsorbed onto PAC was calculated by mass balance. The equilibrium data were analyzed using the Freundlich and the Langmuir isotherms, where $X / M$ and $\mathrm{Ce}$ represent the equilibrium surface and solution concentrations, respectively. In the present study, equilibrium surface concentration has the usual $X / M$ definition, i.e., is the amount adsorbed at equilibrium per mass of carbon, whereas the surface concentration applies for the amount adsorbed after $1 \mathrm{~h}$ of contact time per mass of carbon.

\section{Results ans discussion}

Fig. 2a presents the adsorption kinetics of MC-LR, MC-LY, MC-LW, and MC-LF in Milli-Q water. Despite the differences in charge, hydrophobicity, and initial concentration, no significant differences are found between the adsorption rates of the four microcystin variants. Fast kinetics of adsorption are observed, as expected, taking into account PAC Norit SA-UF characteristics: very fine particles with diameter $6 \mu \mathrm{m}$ and adequate porosity. This PAC has great mesopore $(20-500 \AA)$ and also important secondary micropore $(8-20 \AA)$ volumes and it was proven that MC-LR diameter is between 12 and $26 \AA$ [35], consistent with adsorption in those pores. Fig. $2 \mathrm{~b}$ shows the rates of adsorption of NOM surrogates (AHA, TA, SA) in Milli-Q water. For the same PAC dose, $20 \mathrm{mg} / \mathrm{L}$, and identical initial concentration, TA has the highest rate of adsorption, while AHA has the slowest adsorption kinetics. This difference may 


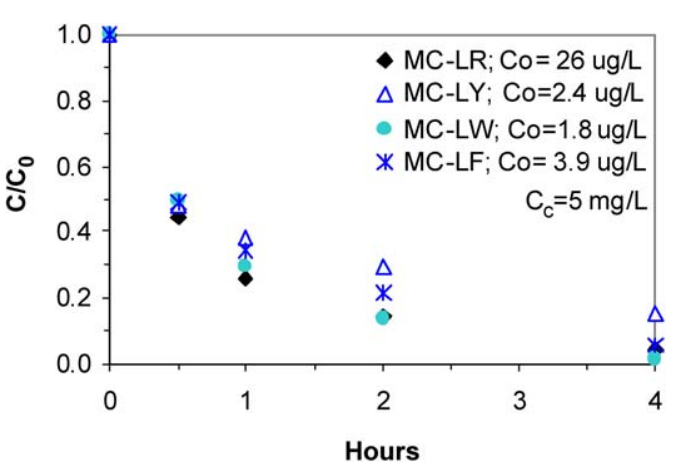

(a)

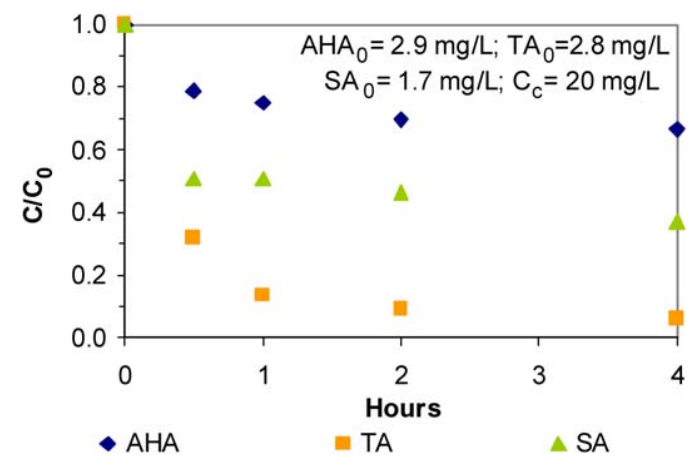

(b)

Fig. 2. Adsorption kinetics in Milli-Q water for (a) microcystin variants and (b) NOM surrogates.

be attributed to the higher molecular weight of AHA causing a slower rate of diffusion through the narrow pores of PAC Norit SA-UF. As shown in Table 2, this PAC has $733 \mathrm{~m}^{2} / \mathrm{g}$ of surface area in micropores ( $66 \%$ of the total) and AHA adsorption sites are probably sterically limited to the larger mesopores. This means less easily accessed surface area (slow kinetics) and also low adsorption capacity, shown by the plateau found at high $C / C_{0}$ values (ca. 0.7 ) after $2 \mathrm{~h}$ of contact time.

Amongst the model compounds, TA has the molecular weight closest to MC-LR, and it is therefore expected to adsorb in the same pores. Actually, MC-LR and TA have similar kinetics, although surface concentrations (after $1 \mathrm{~h}$ of adsorption) are quite different, 3.8 and $122 \mathrm{mg} / \mathrm{g}$, respectively.

SA has the lowest molecular weight (138 Da) and an initial concentration slightly lower than TA and AHA; however, an intermediate rate of adsorption was obtained, together with an intermediate adsorbability (expressed by the plateau at $C / C_{0}$, ca. 0.4 after $2 \mathrm{~h}$ of contact time). This may be due both to its high hydrophilicity and to its adsorption mainly in primary micropores, not so abundant in this PAC.

\subsection{Effect of monovalent ion $\left(K^{+}\right)$}

Figs. 3-6 show the data obtained in the ionic strength studies with monovalent salt $(\mathrm{KCl})$ on $\mathrm{SA}$, microcystin, TA, and AHA adsorption kinetics, respectively.

For a surface concentration of $40-48 \mathrm{mg} \mathrm{SA} / \mathrm{g}$ PAC (after $1 \mathrm{~h}$ of contact time), the increase in $\mathrm{KCl}$ concentration has a negligible effect on SA adsorption kinetics (Fig. 3). Similarly,

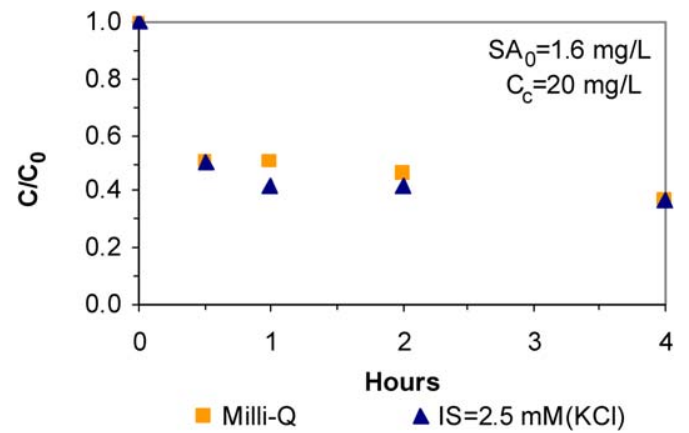

Fig. 3. Adsorption kinetics of salicylic acid in Milli-Q water and in $\mathrm{KCl}$ electrolyte with an ionic strength of $2.5 \mathrm{mM}$.

$\mathrm{K}^{+}$addition brings about only a small change in the MC-LR uptake (Fig. 4), even for an ionic strength of $100 \mathrm{mM}$, and has a very slight adsorption enhancing effect for TA (Fig. 5), results obtained with a surface concentration of $3.3-3.8 \mathrm{mg} / \mathrm{g}$ and $122 \mathrm{mg} / \mathrm{g}$, respectively. For the latter surface concentration, increasing $\mathrm{KCl}$ concentration has a greater positive effect on AHA adsorption. Comparing MC-LR with the other microcystin variants, the effect of monovalent ions was distinct, as the variants showed an enhancement effect with $\mathrm{KCl}$ addition, mainly for the highest ionic strength and first hour of adsorption. A shielding effect on the intermolecular electrostatic repulsions may be the explanation, as MC-LY, LW, and LF have a stronger negative net charge than MC-LR (Table 1).

A general comparison of the results indicates that the impact of potassium cations on model compound adsorption seems to depend upon the molecular size, larger molecules suffering stronger positive impacts. These results are in agreement with those obtained by Kilduff et al. [11] and Li et al. [20].

One effect attributed to monovalent ions seems to be a reduction of the intramolecular charge repulsion (functional group repulsion) with a subsequent molecular reduction by coiling, folding, or compression, enabling the molecule to access a greater fraction of the adsorbent total surface area and facilitating its transport through the narrow pores of carbon. On the other hand, ionic strength may also influence the electrostatic interactions through a shielding effect that is able to improve adsorption by reducing the intermolecular repulsions, or to decrease adsorption by diminishing the electrostatic attractions. According to the results of Newcombe [17], this effect depends upon the adsorbate concentration in the PAC surface.

Since AHA, TA, and SA carry opposite charges in relation to PAC surface in the studied $\mathrm{pH}$ range (4-6) and all adsorption kinetics were determined at high surface concentrations (36-122 mg/g PAC), an enhanced adsorption effect caused by $\mathrm{KCl}$ addition was expected with diminishing lateral repulsions. However, this was only verified for the larger molecules tested, the AHA. So it seems clear that besides surface concentration, the molecular size is another important factor to consider when evaluating the ionic strength effect on PAC adsorption. A reasonable explanation is that the ionic strength causes a reduction in the molecular size, and that change is more significant for larger molecules, which are able to access additional surface area, usually not available. 

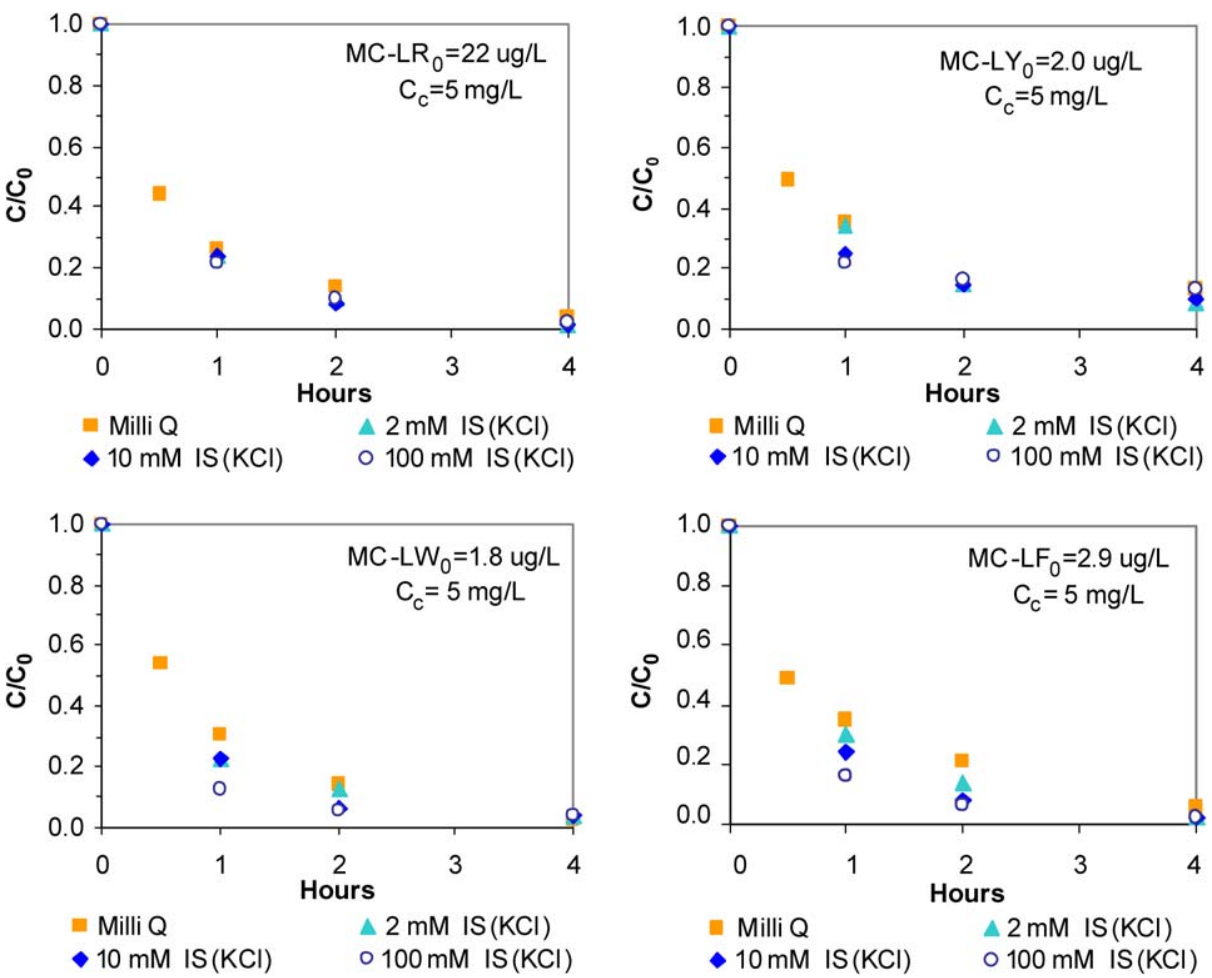

Fig. 4. Adsorption kinetics of microcystin variants in Milli-Q water and in three $\mathrm{KCl}$ electrolytes of increasing ionic strength: 2 , 10 , and $100 \mathrm{mM}$.

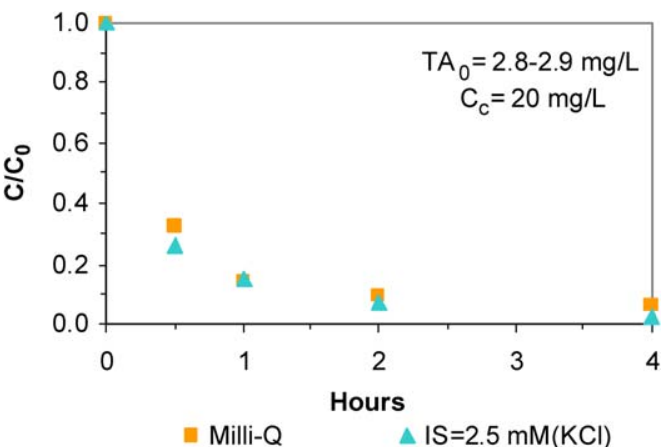

Fig. 5. Adsorption kinetics of tannic acid in Milli-Q water and in $\mathrm{KCl}$ electrolyte with an ionic strength of $2.5 \mathrm{mM}$.

However, while no significant change in MC-LR uptake was observed with $\mathrm{KCl}$ addition, an enhancement effect on the rate of adsorption was detected for MC-LY, MC-LW, and MC-LF, probably due to the solute shrinkage (promoted by the high ionic strength), which increased its diffusion rate. Adsorption isotherms with Milli-Q water and two different $\mathrm{KCl}$ concentrations were performed in order to analyze its effect on the adsorption capacity and intensity at equilibrium. Results are presented in Table 4 and Fig. 7. MC-LW and MC-LF isotherm data are not presented, for they could never be detected at equilibrium.

Fig. 7 reveals that the isotherm curve stabilizes after an initial marked increase, which is interpreted as saturation. The Freundlich equation cannot be applied to all values of $C_{\mathrm{e}}$ as when saturation is achieved $(X / M$ is constant and independent of $C_{\mathrm{e}}$ increase), this equation no longer applies [39]. Conse-

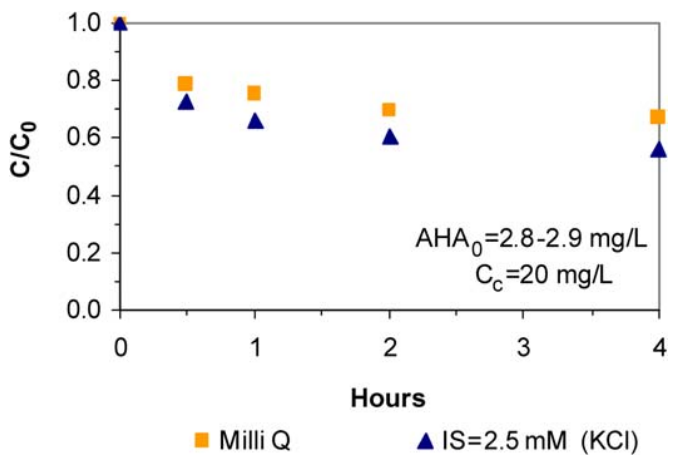

Fig. 6. Adsorption kinetics of Aldrich humic acid in Milli-Q water and in $\mathrm{KCl}$ electrolyte with an ionic strength of $2.5 \mathrm{mM}$.

quently, better curve fitting is obtained with the Langmuir equation, which will thus be used in subsequent data interpretation.

The adsorption capacity of MC-LR given by the Langmuir equation, $a$, is similar for Milli-Q water and for higher ionic strength, 2.5 and $10 \mathrm{mM}(\mathrm{KCl})$. It was also found that $b$, which is related to the energy of adsorption, is alike for Milli-Q water and $2.5 \mathrm{mM}$ and is slightly higher for the greatest ionic strength, suggesting that smaller and higher energy pores are being occupied. This may be explained by a small shrinkage of MC-LR in the more concentrated electrolyte solution.

For the studied range of equilibrium surface concentrations $(5.0-14.0 \mathrm{mg} / \mathrm{g}$ for MC-LR ) no crossover points were observed, which suggests that the enhanced adsorption mode must prevail throughout the studied $X / M$ range.

Analogous adsorption isotherms were also determined for tannic acid, the model compound with a molecular weight more 
Table 4

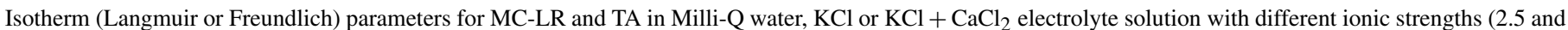
$10 \mathrm{mM})$

\begin{tabular}{|c|c|c|c|c|c|c|}
\hline & Parameters & Milli-Q & $\begin{array}{l}\mathrm{IS}=2.5 \mathrm{mM} \\
(\mathrm{KCl})\end{array}$ & $\begin{array}{l}\mathrm{IS}=10 \mathrm{mM} \\
(\mathrm{KCl})\end{array}$ & $\begin{array}{l}\mathrm{IS}=2.5 \mathrm{mM} \\
\left(\mathrm{KCl}+\mathrm{CaCl}_{2}\right)\end{array}$ & $\begin{array}{l}\mathrm{IS}=10 \mathrm{mM} \\
\left(\mathrm{KCl}+\mathrm{CaCl}_{2}\right)\end{array}$ \\
\hline \multirow[t]{3}{*}{ MC-LR } & $a(\mu \mathrm{g} / \mathrm{mg})$ & 13.0 & 14.4 & 13.2 & 14.8 & 17.0 \\
\hline & $b(\mathrm{~L} / \mu \mathrm{g})$ & 1.8 & 1.6 & 2.9 & 1.5 & 1.4 \\
\hline & $R^{2}$ & 0.9986 & 0.9983 & 0.9996 & 0.9970 & 0.9997 \\
\hline \multirow[t]{3}{*}{ TA } & $K_{\mathrm{f}}(\mu \mathrm{g} / \mathrm{mg}) /(\mathrm{L} / \mu \mathrm{g})^{1 / n}$ & 38.5 & 0.21 & 0.01 & - & - \\
\hline & $1 / n$ & 0.49 & 0.67 & 1.3 & - & - \\
\hline & $R^{2}$ & 0.9320 & 0.9297 & 0.9951 & - & - \\
\hline
\end{tabular}

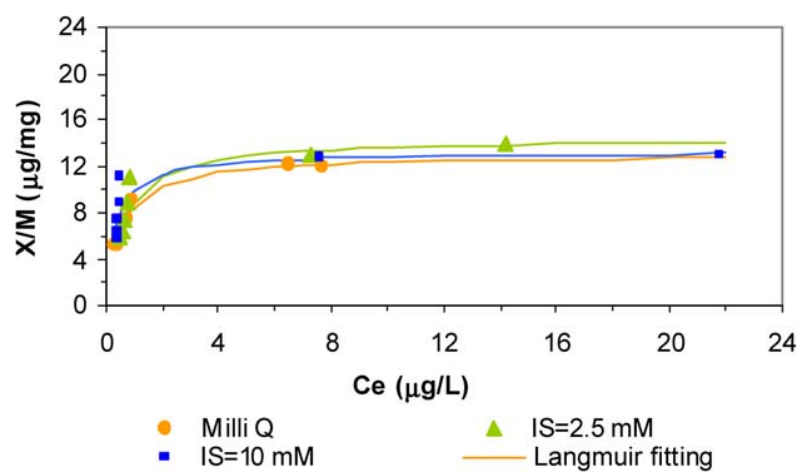

Fig. 7. Adsorption isotherms of MC-LR in Milli-Q water and in $\mathrm{KCl}$ electrolytes with ionic strengths of 2.5 and $10 \mathrm{mM}$.

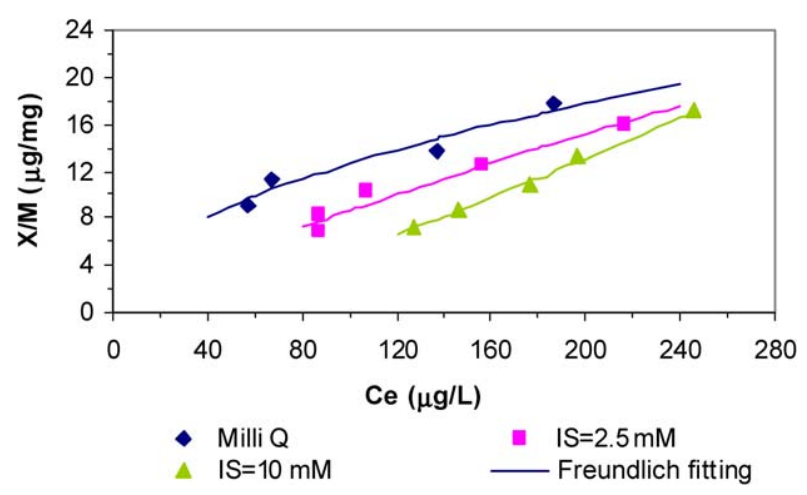

Fig. 8. Adsorption isotherms of tannic acid in Milli-Q water and in $\mathrm{KCl}$ electrolytes with ionic strengths of 2.5 and $10 \mathrm{mM}$.

comparable to MC-LR, for a surface concentration range identical to the one studied for MC-LR (Fig. 8 and Table 4).

Fig. 8 shows that the adsorption isotherm shifted its position downward and to the right as the electrolyte concentration increased, indicating a decrease in the adsorption capacity. This is confirmed by data in Table 4, for in the presence of $\mathrm{KCl}$ the adsorption capacity parameter, $K_{\mathrm{f}}$, shows a marked decrease. The Freundlich value $1 / n$, the heterogeneity parameter of the surface site energy distribution, shows a small increase with $\mathrm{K}^{+}$ addition, which indicates a lower adsorption intensity, although the differences are not as substantial as for $K_{\mathrm{f}}$. These results agree with a reduced screening regime occurring at low equilibrium surface concentrations $(6-18 \mathrm{mg} / \mathrm{g})$, where attractive electrostatic interaction dominates the adsorption mechanism. Thus, an increase in ionic strength causes a shielding effect, di-

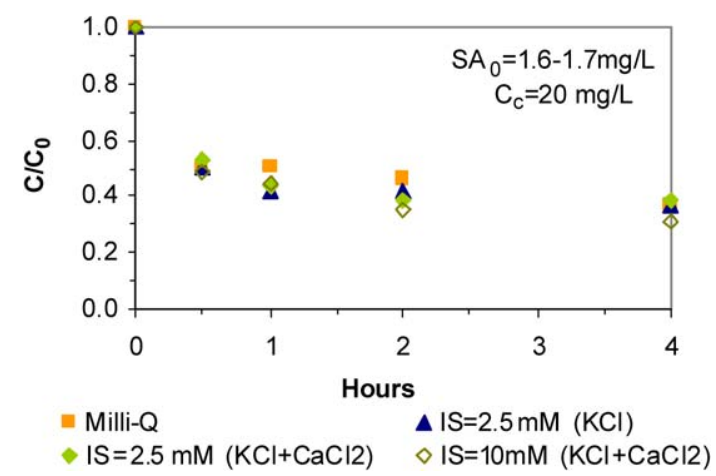

Fig. 9. Adsorption kinetics of SA in Milli-Q water, and in $\mathrm{KCl}$ and $\mathrm{KCl}+\mathrm{CaCl}_{2}$ electrolytes with an ionic strength of 2.5 and $10 \mathrm{mM}$.

minishing the attraction and causing a decrease in adsorption. However, the results of TA kinetics have previously shown that for high surface concentrations $(122 \mathrm{mg} / \mathrm{g}), \mathrm{K}^{+}$addition had a slight positive effect on adsorption (in Fig. 5 equilibrium has almost been reached after 2-4 h of contact time). Therefore, it seems that between surface concentrations of 18 and $122 \mathrm{mg} / \mathrm{g}$ there must be a crossover point corresponding to a transition regime, which confirms Newcombe's and co-authors [17,18] conclusions for NOM.

For identical surface concentrations, different ionic strength impacts were observed on tannic acid and MC-LR, suggesting different adsorption regimes, which are probably due to molecular differences in size and charge.

\subsection{Effect of divalent ion $\left(\mathrm{Ca}^{2+}\right)$}

Figs. 9-12 show the effect of potassium and calcium ions on SA, microcystin, TA, and AHA adsorption, allowing comparisons to be made for the same ionic strength. All $\mathrm{KCl}+\mathrm{CaCl}_{2}$ and $\mathrm{KCl}+\mathrm{MgSO}_{4}$ solutions were prepared with a background ionic strength of $1 \mathrm{mM}$ using $\mathrm{KCl}$ and the remaining ionic strength was completed with $\mathrm{CaCl}_{2}$ or $\mathrm{MgSO}_{4}$ addition.

These figures show that, just as with $\mathrm{K}^{+}$, the impact of $\mathrm{Ca}^{2+}$ on model compounds depends on their molecular size. For identical conditions, increasing calcium dose shows a similar effect to potassium on SA adsorption and even for a $10 \mathrm{mM}$ ionic strength, negligible changes are observed (Fig. 9). For MC-LR adsorption (Fig. 10), calcium addition presents a positive effect, especially at higher concentrations (10 and $100 \mathrm{mM}$ ionic strength) and for the first hour of adsorption. Analogous results 

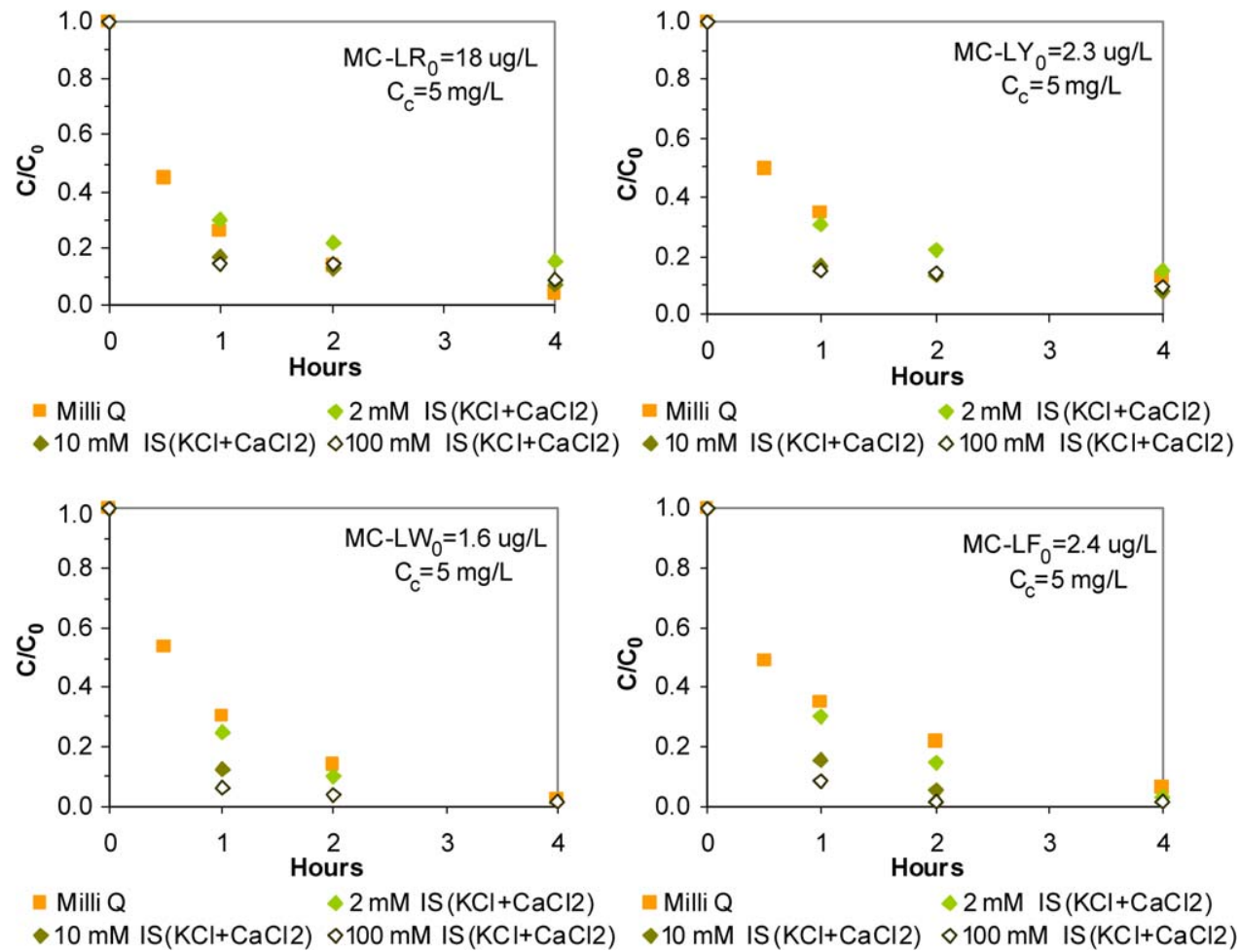

Fig. 10. Adsorption kinetics of microcystin variants in Milli-Q water and in three $\mathrm{KCl}+\mathrm{CaCl}_{2}$ electrolytes of increasing ionic strength: 2 , 10 , and $100 \mathrm{mM}$.

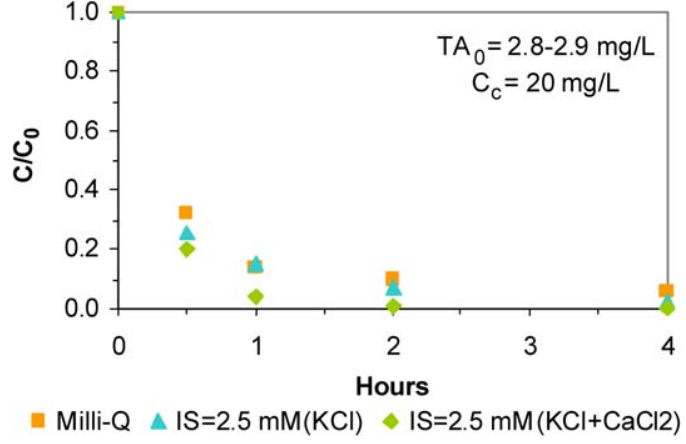

Fig. 11. Adsorption kinetics of TA in Milli-Q water and in $\mathrm{KCl}$ and $\mathrm{KCl}+$ $\mathrm{CaCl}_{2}$ electrolytes with an ionic strength of $2.5 \mathrm{mM}$.

were observed for the other microcystin variants, once again with further enhancement. A more pronounced enhancing effect was also observed for TA (Fig. 11) and, particularly, for humic acid (Fig. 12). For AHA adsorption, calcium and magnesium ions yield quite close curves, showing a similar effect of these ions.

A general comparison of the results shows that calcium addition has no effect on SA and has a positive effect on the remaining compounds. Comparing mono- and divalent ion influence, it is clear that the latter have a more pronounced effect. Since the experiments were conducted under identical conditions, adsorption kinetics are directly comparable, so it seems that calcium may have two supplementary effects in relation to potassium: (1) new adsorption sites are created and/or (2) an incremental shielding effect is obtained, diminishing intra- and intermolecular repulsions.

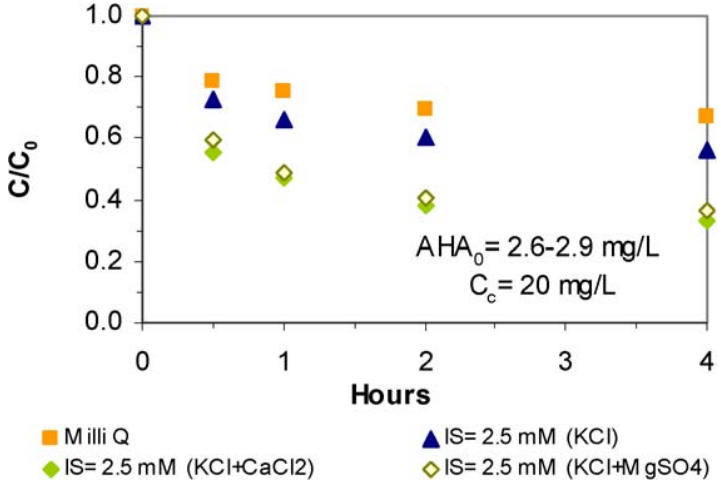

Fig. 12. Adsorption kinetics of AHA in Milli-Q water, and in $\mathrm{KCl}$, $\mathrm{KCl}+\mathrm{CaCl}_{2}$, and $\mathrm{KCl}+\mathrm{MgSO}_{4}$ electrolytes with an ionic strength of $2.5 \mathrm{mM}$.

Kilduff et al. [11] and Andelkovic et al. [38] observed that calcium ions may cause aggregation of humic molecules through cationic bridges and, at sufficiently high concentrations, precipitation may occur [11]. Nonetheless, Randtke and Jepsen [7] showed that although the removal of humic acid involved the destabilization and precipitation of the organic substances by the presence of calcium and magnesium, such effects were small when compared to their effects on the adsorption capacity of adsorbents.

Adsorption isotherms were also performed for MC-LR in Milli-Q water and in two $\mathrm{CaCl}_{2}$ electrolyte solutions (ionic strength of 2.5 and $10 \mathrm{mM}$ ) in order to analyze the adsorption capacity and intensity at equilibrium, and compare them with the $\mathrm{KCl}$ data previously obtained. Results are presented in Table 4 and Fig. 13. 


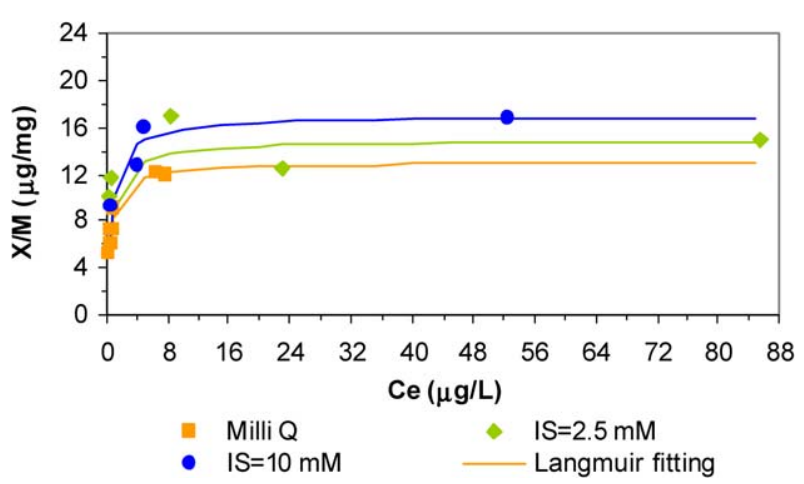

Fig. 13. Adsorption isotherms of MC-LR in Milli-Q water and in $\mathrm{KCl}+\mathrm{CaCl}_{2}$ electrolytes with ionic strengths of 2.5 and $10 \mathrm{mM}$.

Once again it is observed that, in the studied $X / M$ range, the MC-LR isotherm describes the initial increase for equilibrium concentrations up to ca. $10 \mu \mathrm{g} / \mathrm{L}$, after which it stabilizes and achieves saturation. Since the Freundlich model does not apply in this situation, the Langmuir parameters will be analyzed. The adsorption capacity for MC-LR (a) increases with increasing calcium concentration, whereas the adsorption intensity (b) is practically the same for all solutions.

As previously found with $\mathrm{KCl}$ electrolytes, for the studied $X / M$ range of MC-LR $(5.3-18.7 \mathrm{mg} / \mathrm{g})$, no intersection point was observed between the isotherm curves, i.e., no transition regime has occurred. The fact that potassium and calcium addition both promoted a microcystin adsorption enhancement (although to a much lower extent for potassium) may be interpreted as screening enhanced regime behavior. The transition regime must then occur for lower surface concentrations, which are difficult to study due to analytical limitations.

\section{Summary and conclusions}

The effect of mono- and divalent cations on the adsorption of four microcystins (MC-LR, MC-LY, MC-LW, and MC-LF) and NOM surrogates onto PAC Norit SA-UF was studied through adsorption kinetics and isotherm tests. Experimental results indicate that the ionic strength effect depends on the cation charge (mono- or divalent) and on the adsorbate surface concentration and molecular size.

Microcystin-LR isotherms and kinetics showed no significant change in the MC-LR uptake with the $\mathrm{KCl}$ addition. In turn, calcium addition increased the rate of adsorption of MCLR and had a positive effect on its adsorption capacity, although the adsorption intensity seemed not to be affected. These results were interpreted in terms of changes in MC-LR configuration occurring mainly with calcium addition. $\mathrm{KCl}$ and $\mathrm{CaCl}_{2}$ both presented a stronger enhancement effect on the adsorption kinetics of the other microcystin variants. Since these data may be limited by the low initial concentration of these microcystin variants, further studies using higher concentrations are necessary to clarify these results. MC-LR isotherms with two different salt concentrations $\left(\mathrm{KCl}\right.$ or $\left.\mathrm{CaCl}_{2}\right)$ indicated that, for the equilibrium surface concentration range studied (5.3$18.7 \mathrm{mg} / \mathrm{g}$ ), an enhanced adsorption regime prevails, since no crossover points between curves were observed. One possibility is that the transition regime occurs for very low surface concentrations that are difficult to study due to analytical limitations.

Among NOM surrogates, TA had the higher rate of adsorption in Milli-Q water, while AHA had the slowest adsorption kinetics. This difference may be attributed to the higher molecular weight of AHA causing a slower rate of diffusion through the narrow pores of PAC Norit SA-UF.

For identical surface concentration and ionic strength, the impact of $\mathrm{K}^{+}$and $\mathrm{Ca}^{2+}$ ions on the adsorption kinetics of NOM surrogates depends on the adsorbate molecular size. Potassium addition only improved the rate of adsorption of the larger molecules, the humic acid. With calcium, negligible changes in salicylic acid adsorption were observed, while an enhancing effect on the rate of adsorption of tannic acid and, particularly, of humic acid was found. A reasonable explanation is that the ionic strength reduces the molecular size (reduction of intramolecular charge repulsion) and that change is more significant for larger molecules, facilitating their transport through the narrow pores of carbon and enabling them to access additional surface area, which is usually not available.

For tannic acid, although no isotherms were performed in an adequate $X / M$ range for the transition regime to occur with salt addition, different effects were observed for kinetics (high $X / M$ ) and isotherms (low $X / M$ ). At low surface concentrations $(6-18 \mathrm{mg} / \mathrm{g})$, increasing ionic strength decreased adsorption, and at higher surface concentrations $(122 \mathrm{mg} / \mathrm{g})$, salt addition presented a beneficial effect on the adsorption. Consequently, it seems that between surface concentrations of 18 and $122 \mathrm{mg} / \mathrm{g}$ there must be a crossover point corresponding to a transition regime, as proposed by other authors for NOM.

\section{Acknowledgments}

The authors would like to thank FCT (Science and Technology Foundation, Portugal) for providing a Ph.D. scholarship to Margarida Campinas. Special thanks are also addressed to Águas do Algarve, SA (Portugal), for funding this project.

\section{References}

[1] G. Newcombe, D. Cook, S. Brooke, L. Ho, N. Slyman, Environ. Technol. 24 (3) (2003) 299.

[2] G.A. Codd, Ecol. Eng. 16 (2000) 51.

[3] M.J. Rosa, T. Cecílio, M. Ribau Teixeira, M. Viriato, R. Coelho, H. Lucas, Water Sci. Technol. Water Supply 4 (5-6) (2005) 343.

[4] M. Ribau Teixeira, M.J. Rosa, Sep. Purif. Technol. 46 (2005) 192.

[5] C.W.K. Chow, M. Drikas, J. House, M.D. Burch, R.M.A. Velzeboer, Water Res. 33 (15) (1999) 3253.

[6] J.J. McCreary, V.L. Snoeyink, Water Res. 14 (1980) 151.

[7] S.J. Randtke, C.P. Jepsen, J. Am. Water Works Assoc. 74 (2) (1982) 84.

[8] W.J. Weber, T.C. Voice, A. Jodellah, J. Am. Water Works Assoc. 75 (12) (1983) 612.

[9] R.S. Summers, P.V. Roberts, J. Colloid Interface Sci. 122 (1988) 382.

[10] P. LaFrance, M. Mazet, J. Am. Water Works Assoc. 81 (4) (1989) 155.

[11] J.E. Kilduff, T. Karanfil, W.J. Weber Jr., Environ. Sci. Technol. 30 (4) (1996) 1336.

[12] J. Duan, F. Wilson, N. Graham, J.H. Tay, Desalination 151 (2002) 53.

[13] A.A.M. Daifullah, B.S. Girgis, H.M.H. Gad, Colloids Surf. A Physicochem. Eng. Aspects 235 (2004) 1.

[14] J. Fettig, Water Sci. Technol. 40 (9) (1999) 173. 
[15] J.E. Kilduff, T. Karanfil, Water Res. 36 (2002) 1685.

[16] G. Newcombe, M. Drikas, Carbon 35 (9) (1997) 1239.

[17] G. Newcombe, Water Sci. Technol. 40 (9) (1999) 191.

[18] M. Bjelopavlic, G. Newcombe, R. Hayes, J. Colloid Interface Sci. 210 (2) (1999) 271.

[19] S.J. Randtke, V.L. Snoeyink, J. Am. Water Works Assoc. 75 (1983) 406.

[20] F. Li, A. Yuasa, K. Ebie, Y. Azuma, T. Hagishita, Y. Matsui, Water Res. 36 (18) (2002) 4592.

[21] L. Lawton, C. Edwards, J. Chromatogr. A 912 (2001) 191.

[22] P.G.-J. Maagd, A.J. Hendriks, W. Seinen, D. Sijm, Water Res. 33 (3) (1999) 677.

[23] K. Sivonen, G. Jones, in: I. Chorus, J. Bartram (Eds.), Toxic Cyanobacteria in Water: A Guide to Their Public Health Consequences, Monitoring and management, WHO, London, 1999, p. 3.1.

[24] E.-E. Chang, P.-C. Chiang, W.-Y. Tang, S.-H. Chao, H.-J. Hsing, Chemosphere 58 (2005) 1141.

[25] Y.-P. Chin, G. Alken, E. O’Loughlln, Environ. Sci. Technol. 28 (1994) 1853.

[26] E. Yamada, K. Doi, K. Okano, Y. Fuse, Anal. Sci. 16 (2) (2000) 125.

[27] M. Elimelech, S. Hong, J. Membr. Sci. 132 (1997) 159.

[28] G. Crozes, C. Anselme, J. Mallevialle, J. Membr. Sci. 84 (1-2) (1993) 61.
[29] E.C. Devitt, F. Ducellier, P. Cote, M.R. Wiesner, Water Res. 32 (9) (1998) 2563.

[30] S.K. Dentel, A. Jamrah, D. Sparks, Water Res. 32 (12) (1998) 3689.

[31] H. Yamamoto, H.M. Liljestrand, Y. Shimizu, M. Morita, Environ. Sci. Technol. 37 (2003) 2646.

[32] C. Campos, L. Schimmoller, B.J. Mariñas, V.L. Snoeyink, I. Baudin, J.-M. Laîné, J. Am. Water Works Assoc. 92 (8) (2000) 69.

[33] S.G. Yantsios, A.J. Karabelas, Desalination 140 (2001) 195.

[34] Q. Li, V.L. Snoeyink, B.J. Marinas, C. Campos, Water Res. 37 (20) (2003) 4863.

[35] C. Donati, M. Drikas, R. Hayes, G. Newcombe, Water Res. 28 (8) (1994) 1735.

[36] P. Pendleton, R. Schumann, S.H. Wong, J. Colloid Interface Sci. 240 (1) (2001) 1.

[37] J. Meriluoto, L. Spoof, TOXIC European Project "Barriers against Cyanotoxins in Drinking Water" (EVK1-CT00107-2002), Abo Akademi University, Finland, 2003.

[38] T. Andelkovic, J. Perovic, M. Purenovic, D. Andelkovic, Facta Univ. Phys. Chem. Technol. 3 (1) (2004) 79.

[39] V.L. Snoeyink, R.S. Summers, in: American Water Works Association (Ed.), Water Quality and Treatment, Lisbon, 1999, p. 13.1. 